\title{
An Experimental Study on Effect of Steel Corrosion on the Bond-Slip Performance of Reinforced Concrete
}

\author{
Xiaolin Zhang, Xuebing Liang, Zeqiang Wang, Hancheng Huang, and Haijun Zhou \\ Department of civil Engineering, Shenzhen University
}

\begin{abstract}
This paper studied the effects of reinforcement corrosion on bond performance between rebar and concrete. Tests were carried out to evaluate the degradation of bond between reinforcing steel and concrete for different corrosion levels of reinforcing steel. A series of 20 specimens of different concrete strength with various reinforcing steel corrosion levels were designed and manufactured. Each specimen was casted as a $200-\mathrm{mm}$ concrete cube, and a steel rebar was centrally embedded with two stirrups around it. The steel rebar were corroded using an electrochemical accelerated corrosion technique. The corrosion crack opening width and length were recorded after the corrosion process. Then, monolithic pull-out loading tests were carried out on the specimens. The effects of reinforcement corrosion on crack opening, maximum bond stress, and energy dissipation were discussed in detail. It was found that reinforcement corrosion has non-negligible effects on bond performance of reinforcing bar in concrete.
\end{abstract}

Keywords: reinforced concrete, corrosion, bond-slip, pullout, rebar

\section{INTRODUCTION}

While it is known that corrosion of steel reinforcement is a major problem influencing the long-term performance of reinforced concrete infrastructures (Duan, Dai, \& Jin, 2015). It normally occurs due to attack by aggressive agents, such as chloride ions, from the marine environment. Therefore, expansive stresses are induced around corroded steel bars, causing possible cracking, spalling of the concrete cover, and loss of bonding between the steel and concrete (Cairns, Du, \& Law, 2008). Bonding facilitates load transfer across the steel-concrete interface, which is essential for the composite action of reinforced concrete structures. Bonding behaviors primarily dependent on three factors: the compressive strength of concrete, confinement, and the surface of the rebar (deformed or round) (Wu \& Zhao, 2013). Previous studies have been undertaken to evaluate the effects of corrosion on the bond strength (Almusallam, Al-Gahtani, Aziz, \& Rasheeduzzafar 1996; Bhargava, Ghosh, Mori, \& Ramanjam, 2008; Eligehausen, Popov, \& Bertero, 1983; Fang, Gylltoft, Lundgren, \& Plos, 2006; Fang, Lundgren, Chen, \& Zhu, 2004; Kivell, 2012; Mangat \& Elgarf, 1999; Yalciner, Eren, \& Sensoy, 2012). However, little information is available on the effects of concrete strength on bond performance of reinforcing steel in concrete. This is to further study the effects of concrete strength and reinforcement corrosion on bond behavior of reinforcing steel in concrete by both monolithic pull-out loading tests.

\section{TEST SETUP AND PROCEDURE}

\subsection{Test specimen}

The configuration of test specimen followed the previous studies (Zhou, Lu, Xv, Dong, \& Xing, 2015). Specimens consisted of deformed steel rebar set in a concrete prism with two stirrups to provide confinement (Figure 1).

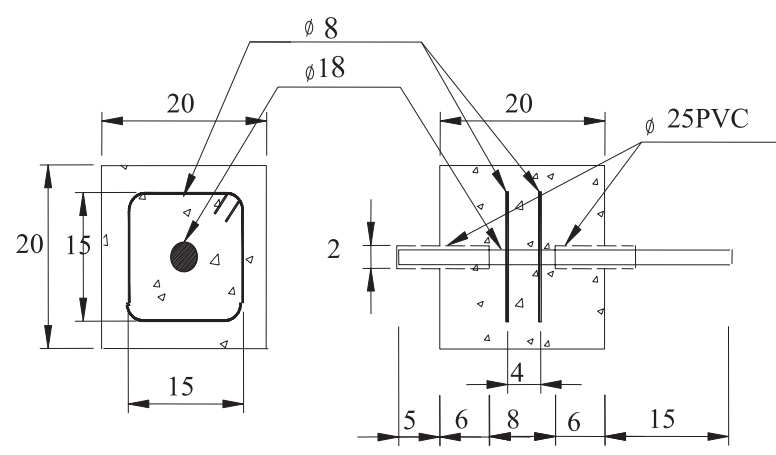

Figure 1. Specimen geometry (Unit: millimeter).

Two PVC pipes were used to limit the bonded length to $80 \mathrm{~mm}$. The bonded length was much less than the development length of the rebar, so the bond stress along the rebar was relatively uniform. The two closely spaced stirrups provided confinement along the bonded length and helped to limit any end effects (Figure 2). Twenty specimens were casted in total in this test: 10 specimens of concrete strength have designed $20 \mathrm{MPa}$, and other 10 specimens of concrete strength have designed $40 \mathrm{MPa}$, as shown in Table 1. 


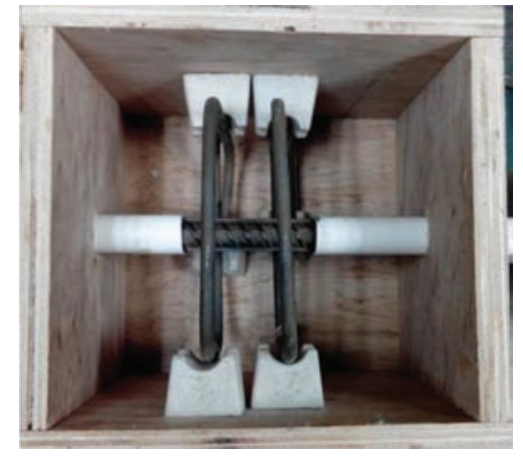

Figure 2. Mould for specimen.

Table 1. Reinforcement corrosion level, maximum crack width, and total length of tested specimens.

\begin{tabular}{|c|c|c|c|c|}
\hline $\begin{array}{l}\text { Specimen } \\
\text { number }\end{array}$ & $\begin{array}{c}\text { Designed } \\
\text { corrosion } \\
(\%)\end{array}$ & $\begin{array}{c}\text { Measured } \\
\text { corrosion } \\
(\%)\end{array}$ & $\begin{array}{l}\text { Total crack } \\
\text { length } \\
\text { (cm) }\end{array}$ & $\begin{array}{l}\text { Maximum } \\
\text { crack } \\
\text { width }(\mathrm{mm})\end{array}$ \\
\hline 1 & 0 & 0.27 & No crack & No crack \\
\hline 2 & 0 & 0.33 & No crack & No crack \\
\hline 3 & 5 & 3.95 & No crack & No crack \\
\hline 4 & 5 & 3.76 & 19 & 0.3 \\
\hline 5 & 10 & 7.17 & 33.4 & 0.42 \\
\hline 6 & 10 & 7.45 & 25.1 & 0.43 \\
\hline 7 & 15 & 10.78 & 39 & 0.3 \\
\hline 8 & 15 & 10.45 & 35.3 & 0.43 \\
\hline 9 & 20 & 13.18 & 53.4 & 0.45 \\
\hline 10 & 20 & 13.56 & 53.3 & 0.4 \\
\hline 11 & 0 & 0.30 & No crack & No crack \\
\hline 12 & 0 & 0.18 & No crack & No crack \\
\hline 13 & 5 & 3.78 & 49.80 & 0.40 \\
\hline 14 & 5 & 4.13 & 37.30 & 0.30 \\
\hline 15 & 10 & 7.74 & 41.10 & 0.80 \\
\hline 16 & 10 & 7.32 & 77.70 & 0.43 \\
\hline 17 & 15 & 11.52 & 88.00 & 0.87 \\
\hline 18 & 15 & 11.87 & 100.20 & 0.50 \\
\hline 19 & 20 & 14.81 & 56.70 & 1.30 \\
\hline 20 & 20 & 14.66 & 52.00 & 1.02 \\
\hline
\end{tabular}

\subsection{Concrete mix design}

The first concrete was designed to have a compressive strength of about $20 \mathrm{MPa}$ with a w/c ratio of 0.6 . The concrete mix per cubic meter was $336.02 \mathrm{~kg}$ ordinary Portland cement, $201.61 \mathrm{~kg}$ water, $725.81 \mathrm{~kg}$ sand, and $1236.56 \mathrm{~kg}$ stone. The second concrete was designed to have a compressive strength of about $40 \mathrm{MPa}$ with a $\mathrm{w} / \mathrm{c}$ ratio of 0.48 . The concrete mix per cubic meter was $418.06 \mathrm{~kg}$ ordinary Portland cement, $200.67 \mathrm{~kg}$ water, $677.26 \mathrm{~kg}$ sand, and $1204.01 \mathrm{~kg}$ stone. Concrete cubes with the dimensions of $100 \mathrm{~mm} \times 100 \mathrm{~mm} \times 100 \mathrm{~mm}$ were also cast for compressive strength testing. And this concrete of two kinds was found to have a 28-day average compressive strength of 20.7 and $44.4 \mathrm{MPa}$.

\subsection{Accelerated corrosion program}

The specimens were corroded using an electrochemical accelerated corrosion technique that involves impressing a direct current through the specimens to accelerate the oxidation process in a $5 \% \mathrm{NaCl}$ solution (Fang et al., 2006). Table 1 lists the tested specimens, the expected mass loss ranged from 0 to $20 \%$. The level of corrosion was roughly estimated according to the mass loss of the rebar to establish different corrosion levels for the reinforcement.

To ensure that only the bonded zone would be corroded, one end of the steel bar was insulated during the corrosion. The lower part of the steel bar was coated with paraffin, and wrapped with insulated plastic membrane (Figure 3).

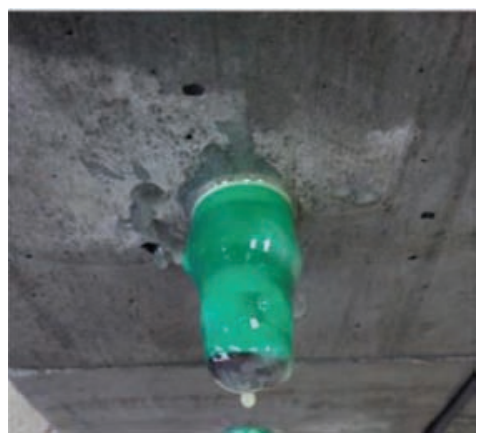

Figure 3. Insulated end of steel bar during corrosion.

The theoretically calculated amount of corrosion products, in terms of the electrolytic time, can be expressed by Faraday's Law:

$$
T=\frac{m_{t} \times 2 \times F}{I \times 55.847}
$$

where $T$ is the corrosion duration time, $m_{t}$ is the mass loss, $I$ is the average electrical current, and $F$ is the Faraday constant.

In this study, the current density was set as $300 \mu \mathrm{A} /$ $\mathrm{cm}^{2}$; the corresponding current in the rebar was $13.57 \mathrm{~mA}$ per specimen. The above current density was smaller than $500 \mu \mathrm{A} / \mathrm{cm}^{2}$ as the maximum current density for electrochemical accelerated corrosion in concrete (Zhou et al., 2015). The specimens were soaked for 5 days prior to application of the current. The accelerated corrosion of the reinforcement was actually carried out for three specimens in series (Figure 4). The experimental research program consisted of testing a total of 20 reinforced concrete specimens with different corrosion levels. The maximum required artificial corrosion process took approximately 92 days. 


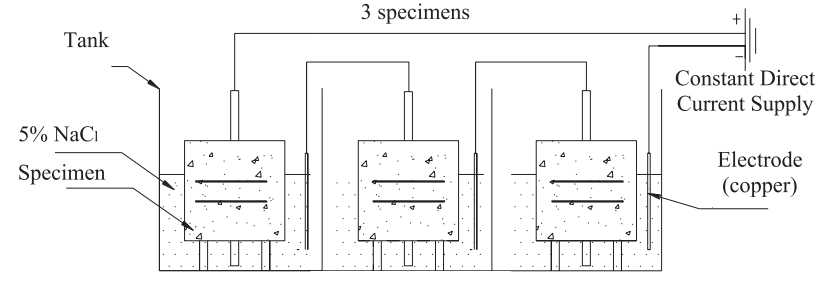

Figure 4. Schematic representation of the electrochemical system.

\subsection{Pull-out loading}

In this experiment, the loading of all the specimens is monolithically increased slip loading with the loading speed of $0.4 \mathrm{~mm} / \mathrm{min}$. The corroded specimens were tested in a loading machine with a specially designed and fabricated loading frame. Figure 5(a) shows the schematic drawing of the loading system.

And Figure 5(b) shows the details of the extensometer installation. Load force was measured through the load cell and the free-end slip was measured using an extensometer with precision of $\pm 0.001 \mathrm{~mm}$.

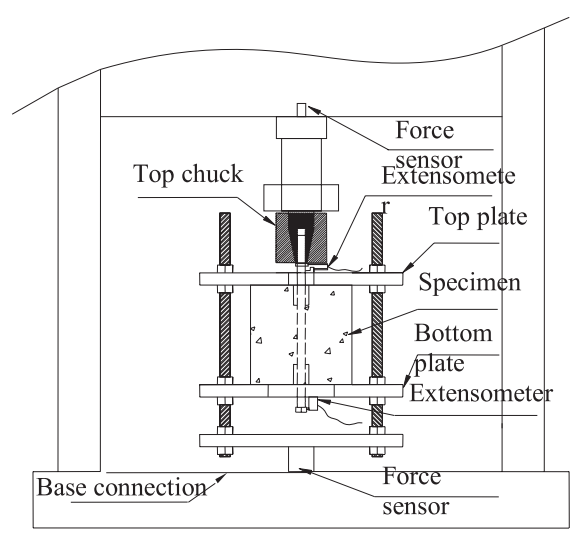

(a) Schematic drawing

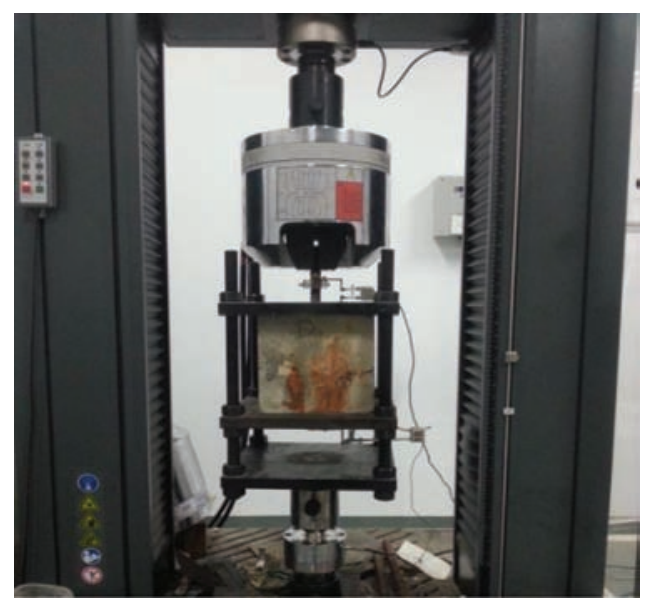

(b) Load device diagram

Figure 5. Loading and measuring system.

\section{TEST RESULTS}

Table 1 lists the measured crack lengths and the corresponding maximum crack width. The crack length was measured by ruler, and the width was measured by width gauge $(3-5 \mathrm{~cm}$ reading once, then calculate the maximum width). The critical mass loss of reinforcement for crack opening to occur was identified as about $4 \%$, but not for any specimens with lower mass loss. It clearly shows an increase in both maximum crack width and total crack length as the reinforcement corrosion level increases. Compared with $20.7 \mathrm{MPa}$ concrete strength specimen, the crack of the 44.4-MPa concrete strength specimen is longer and wider in the case of same corrosion level.

\subsection{Crack opening after artificial corrosion}

As recent studies have shown the potential effects of crack opening on bond performance (Coronelli, Hanjari, \& Lundgren, 2013; Law, Tang, Molyneaux, \& Gravina, 2011), the crack information was recorded in detail in this test. Figure 6 shows corrosion-induced cracks for typical specimen of different rebar corrosion and concrete strength of concrete prism after corrosion process. As the corrosion rate increases, the surface of specimens appeared more and more corrosion products, and there are also increase of the crack number, crack width, and length.

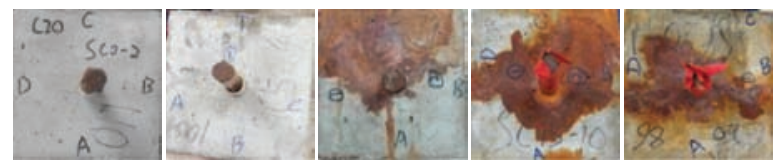

(a)

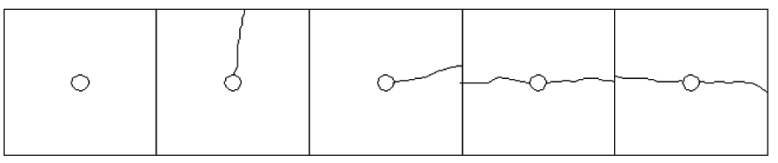

(b)

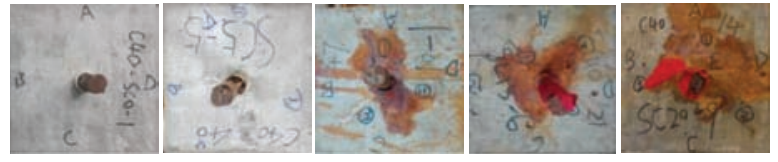

(c)

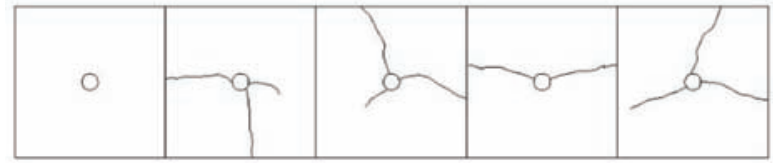

(d)

Figure 6. Corrosion-induced cracks. (a) Typical specimens crack in the one of side and the concrete strength is $20.7 \mathrm{MPa}$, the reinforcement corrosion is $0.33,3.95,7.17,10.45$, and $13.18 \%$ from left to right. (b) Photo of Typical specimens from (a). (c) Typical specimen's crack in the one of side and the concrete strength is 44.4 MPa; the reinforcement corrosion is $0.3,4.13,7.74,11.87$, and $14.66 \%$ from left to right. (d) Photo of Typical specimens from (c). 


\subsection{Measured mass loss of reinforcement}

The reinforcement was cleaned using a $12 \%$ hydrochloric acid solution to remove scale and rust products and weighed before casting the specimens. After the corrosion process and loading test, the corroded reinforcements were retrieved by opening the specimens (Figure 7). Then, they were cleaned and weighed again. Then, the mass loss of each stirrup was derived by the following equation:

$$
\xi_{S}=\frac{m_{s 0}-m_{S}}{m_{s 0}} \times 100 \%
$$

where $m_{s}$ is the mass of steel bar after removal of the corrosion products, and $m_{s 0}$ is the mass of steel bar before corrosion. The mass loss can be regarded as the steel bar area reduction (corrosion rate) considering that artificial corrosion is more uniform than natural pitting corrosion. Table 1 also shows that the expected mass loss agrees well with the actual measured mass loss. From Table 1, it can be seen that the measured corrosion levels were generally lower than the designed ones. The difference in results indicates that the permeability of concrete plays a role in the magnitude of actual corrosion; the permeability of the concrete was not included in the equations for the theoretical calculation of corrosion

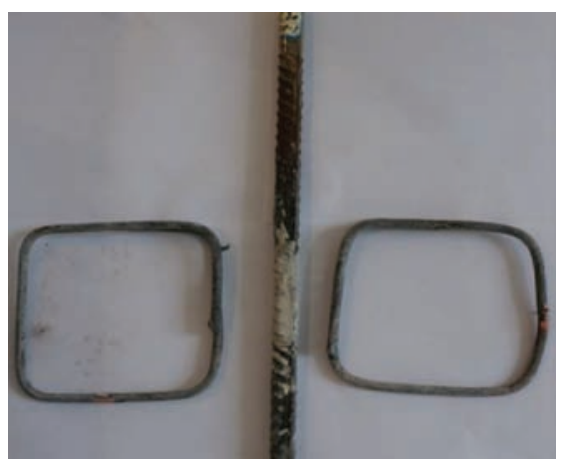

(a)

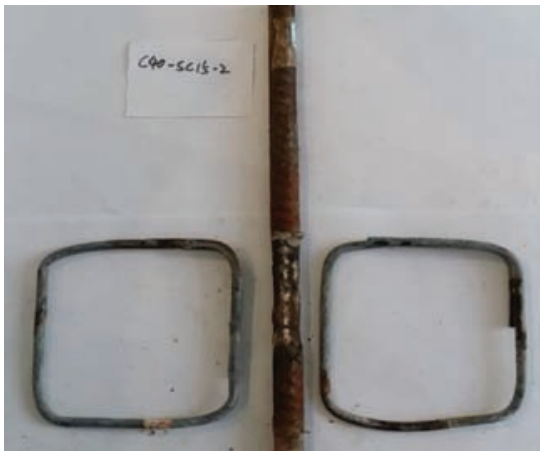

(b)

Figure 7. Corroded reinforcement. (a) (20.7 MPa concrete strength $\xi_{s}=10.45 \%$, specimen No. 8), (b) (44.4 MPa concrete strength $\xi_{S}=11.87 \%$, specimen No. 18 ). amounts. Although the specimens were immersed in the $\mathrm{NaCl}$ solution, it would have taken a period of time for the solution to reach the reinforcement through the concrete cover. Another factor that affects the corrosion may be the heterogeneity of the coarse aggregate within the specimen.

\subsection{Pull-out loading}

Figure 8(a) shows pull-out bond stress-slip curves of the tested specimens of $20.7 \mathrm{MPa}$. The five specimens had different reinforcement corrosion rates (from 0.33 to $13.6 \%$ ). Figure 8 (b) shows pull-out bond stressslip curves of the tested specimens of $44.4 \mathrm{MPa}$. The five specimens had different reinforcement corrosion rates (from 0.3 to $14.81 \%$ ). The bond stress was derived from the measured load force by the following formulation:

$$
\tau=\frac{P}{\pi d l}
$$

where $I$ is the bond length, $d$ is the diameter of rebar, and $P$ is the measured load force.

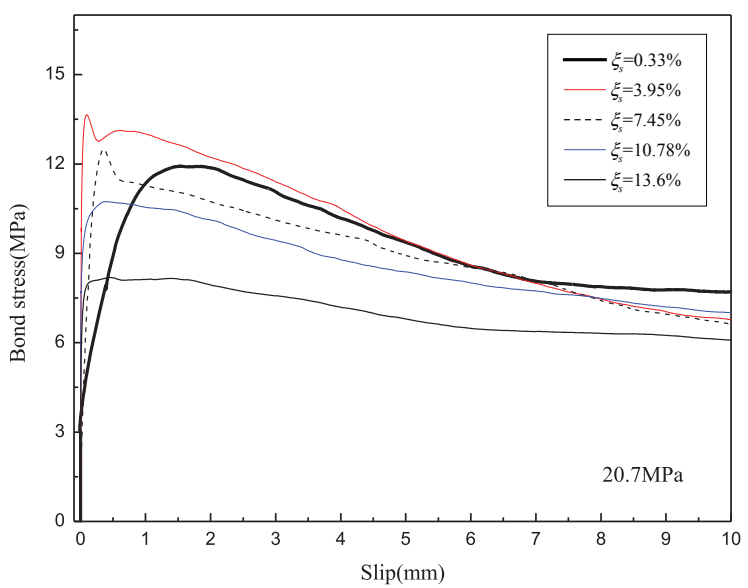

(a)

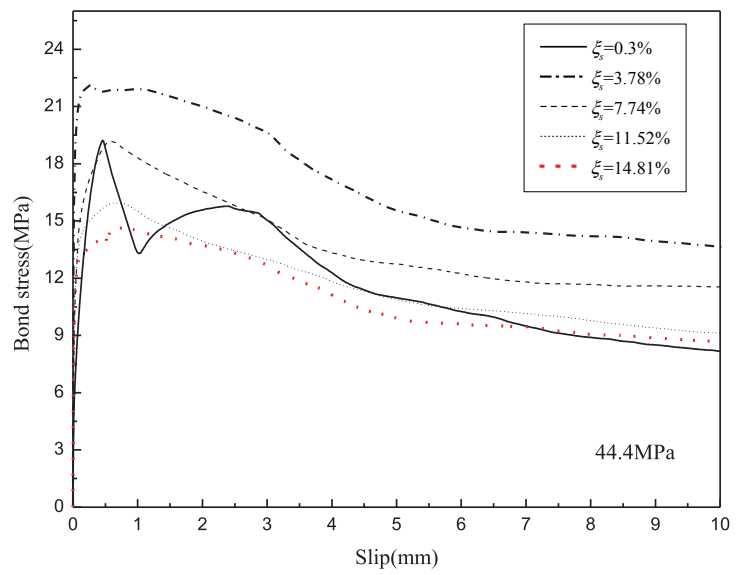

(b)

Figure 8. Bond stress-slip curves under monotonic slip loading. (a) $20.7 \mathrm{MPa}$ and (b) $44.4 \mathrm{MPa}$. 


\subsection{Maximum bond stress}

Figure 9 shows the maximum bond stress vs. reinforcement corrosion ratio. It clearly shows the effects of corrosion. As the corrosion rates increase, the maximum bond stress has increased first and then decreased, and the maximum bond stress is highest for a reinforcement corrosion ratio of about $4 \%$ both two kinds of specimens. With 20.7 MPa specimens, when the degree of corrosion was $13.56 \%$, the maximum bond stress decreased $32 \%$. For 44.4 MPa specimens, however, when the degree of corrosion was $14.66 \%$, the maximum bond stress decreased $9.5 \%$.

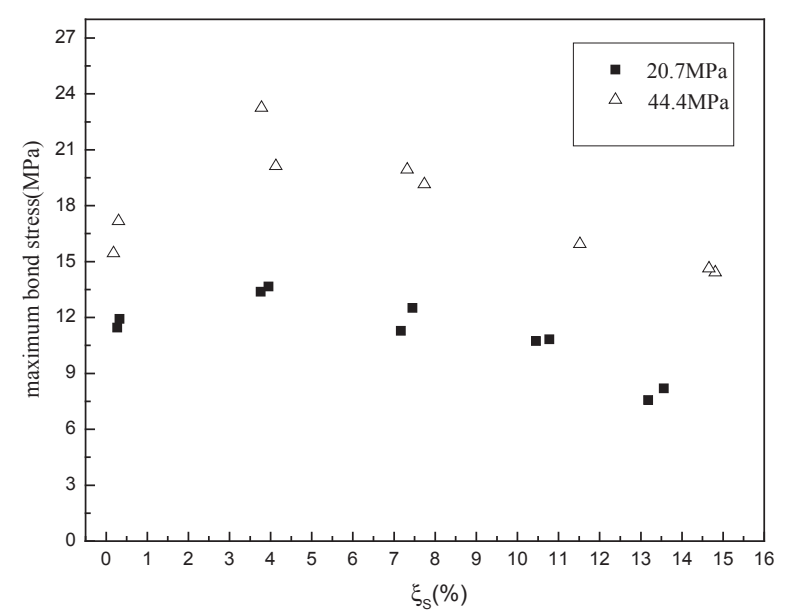

Figure 9. Maximum bond stress vs. reinforcement corrosion ratio.

\subsection{Energy dissipation}

The energy dissipation in pull-out loading was derived by calculating the area of the hysteresis loop in the force-slip curve (0-10 $\mathrm{mm}$ slip). Figure 10 shows the energy dissipation vs. reinforcement corrosion ratio. High strength specimens are more energy consuming than low strength specimens. When the corrosion rates increase, the energy dissipation has increased

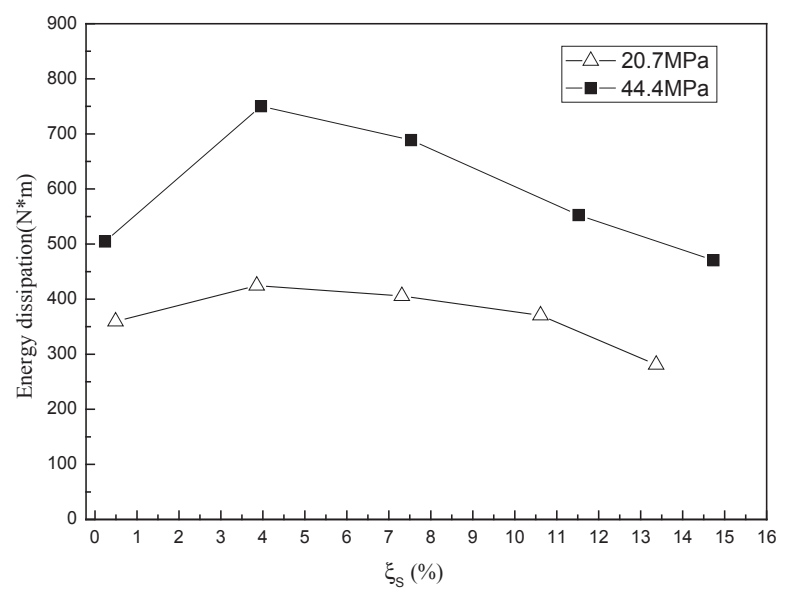

Figure 10. Energy dissipation vs. reinforcement corrosion ratio. first and then decreased. And the energy dissipation is highest for a reinforcement corrosion ratio of about $4 \%$ both two kinds of specimens. It should be noted that, for 20.7 MPa specimens, energy dissipation for a corrosion level of $13.56 \%$ is about $6.77 \%$ lower than that of a corrosion level $0.33 \%$. While for $44.4 \mathrm{MPa}$ specimens, when the degree of corrosion was $14.66 \%$, the energy dissipation decrease $21 \%$.

\section{CONCLUSION}

This paper reported a preliminary study of reinforcement corrosion effects on bond performance of reinforcing steel in concrete. Compare the parameters of bond-slip relation for specimens with concrete strength and corrosion rates. It was found that:

(1) The test results of monotonic slip loading showed that bond strength was very sensitive to corrosion levels and generally decreased with the corrosion level. Bond strength decreased rapidly as the corrosion level increased both in the different strength specimens. The exception is that when the corrosion level was very low, when bond strength increased as the corrosion level increased;

(2) When the lower the concrete strength of the specimens, the degradation of the bond stress is more obvious as the corrosion level increase. With 20.7 MPa specimens, when the degree of corrosion was $13.56 \%$, the maximum bond stress decreased $32 \%$. For $44.4 \mathrm{MPa}$ specimens, however, when the degree of corrosion was $14.66 \%$, the maximum bond stress decreased $9.5 \%$.

(3) When the corrosion rates increase, the energy dissipation has increased first and then decreased, and it is highest for a reinforcement corrosion ratio of about $4 \%$. The degradation of the energy dissipation of lower strength of the specimens is more obvious compared with higher strength of the specimens. For 20.7 MPa specimens, energy dissipation for a corrosion level of $13.56 \%$ is about $6.77 \%$ lower than that of a corrosion level $0.33 \%$. While for $44.4 \mathrm{MPa}$ specimens, when the degree of corrosion was $14.66 \%$, the energy dissipation decrease $21 \%$.

\section{ACKNOWLEDGMENTS}

The work described in this paper was financially supported by the Ministry of Science and Technology for the 973-project (No. 2011CB013604), the National Natural Science Foundation of China (Grant No. 51378313), and the Department of Education of Guangdong Province (Grant No. 2013KJCX0157), to which the writers are grateful. 


\section{REFERENCES}

Almusallam, A. A., Al-Gahtani, A. S., Aziz, A. R., \& Rasheeduzzafar. (1996). Effect of reinforcement corrosion on bond strength. Construction and Building Materials, 10(2), 123-129.

Bhargava, K., Ghosh, A., Mori, Y., \& Ramanjam, S. (2008). Suggested empirical models for corrosioninduced bond degradation in reinforced concrete. ASCE Journal of Structural Engineering, 134, 221-230.

Cairns, J., Du, Y., \& Law, D. W. (2008). Structural performance of corrosion-damaged concrete beams. Magazine of Concrete Research, 60(5), 359-370.

Coronelli, D., Hanjari, K., \& Lundgren, K. (2013). Severely corroded RC with cover cracking. ASCE Journal of Structural Engineering, 139, 221-232.

Duan, A., Dai, J. G., \& Jin, W. L. (2015). Probabilistic approach for durability design of concrete structures in marine environments. ASCE Journal of Materials in Civil Engineering, 27(2), 1-8.

Eligehausen, R., Popov, E. P., \& Bertero, V. V. (1983). Local bond stress-slip relationships of deformed bars under generalized excitations (EERC Report No. UCB/EERC-83/23). Berkeley, CA: University of California at Berkeley.

Fang, C. Q., Gylltoft, K., Lundgren, K., \& Plos, M. (2006). Effect of corrosion on bond in reinforced concrete under cyclic loading. Cement and Concrete Research, 36(3), 548-555.
Fang, C. Q., Lundgren, K., Chen, L., \& Zhu, C. (2004). Corrosion influence on bond in reinforced concrete. Cement and Concrete Research, 34(11), 2159-2167.

Kivell, A. (2012). Effects of bond deterioration due to corrosion on seismic performance of reinforced concrete structures (Master thesis). University of Canterbury, New Zealand.

Law, D. W., Tang, D. L., Molyneaux, T. K. C., \& Gravina, R. (2011). Impact of crack width on bond: Confined and unconfined rebar. Materials and Structures, 44(7), 1287-1296.

Mangat, P. S., \& Elgarf, M. S. (1999). Bond characteristics of corroding reinforcement in concrete beams. Materials and Structures, 32, 89-97.

Wu, Y. F., \& Zhao, X. M. (2013). Unified bond stressslip model for reinforced concrete. ASCE Journal of Structural Engineering, 139(11), 1951-1962.

Yalciner, H., Eren, O., \& Sensoy, S. (2012). An experimental study on the bond strength between reinforcement bars and concrete as a function of concrete cover, strength and corrosion level. Cement and Concrete Research, 42(5), 643-655.

Zhou, H., Lu, J., Xv, X., Dong, B., \& Xing, F. (2015). Effects of stirrup corrosion on bond-slip performance of reinforcing steelin concrete: An experimental study. Construction and Building Materials, 93, 257-266. 